Dressler, R., Chu, M-W., Crossman, K., \& Hilman, B. (2019). Quantity and quality of uptake: Examining surface and meaning-level feedback provided by peers and an instructor in a graduate research course. Assessing Writing, 39(1), 14-24, doi:10.1016/j.asw.2018.11.001

\title{
Quantity and Quality of Uptake: Examining Surface and Meaning-Level Feedback Provided by Peers and an Instructor in a Graduate Research Course
}

\begin{abstract}
We examine the quantity and quality of uptake of surface-level and meaning-level feedback provided by peers and an instructor on writing assignments in an online graduate-level research course at a North American English-medium university. In this study, the instructor and peers ( 9 graduate students) endeavored to provide feedback that was timely, specific and embedded in writing (Wolsey, 2008). Students integrated this feedback on their writing assignments approximately $84.89 \%$ of the time, with the rate of uptake for instructor-provided feedback slightly higher than that of peer-provided feedback. This study also found that students addressed surface-level feedback focusing on writing mechanics, more frequently than meaninglevel feedback, which focuses on argumentation, flow, and content. Overall, instructor surfacelevel feedback was most likely to be taken up, peer meaning-level feedback items was least likely. These results reveal the need for student training in the provision and uptake of feedback in online graduate contexts and beyond.
\end{abstract}

Key words: Formative Feedback, Graduate Studies, Peer Feedback, Instructor Feedback, Uptake, Graduate-level Writing 


\section{Introduction}

Embedded formative feedback, in the form of peer and instructor feedback on drafts, is a potentially useful feature of graduate study course design. This feedback can take the form of constructive peer and instructor commentary on drafts (Sambell, 2011) with the goal of improving student writing by offering suggestions or modifications to produce higher quality final submissions and encourage focused editing. Embedded formative feedback is found in many English as an Additional Language (EAL) classes and, to a lesser extent, in undergraduate education; however, is much less common in graduate-level research courses. Baker (2016) noted that in courses with course-embedded peer and instructor feedback, students begin their writing earlier and substantially revise their drafts due to the formative feedback received. These findings suggest that embedding peer and instructor feedback into course design is valuable and potentially applicable to contexts outside of EAL or undergraduate courses, such as the one in this study.

Despite this observed potential, embedding formative feedback has received very little attention in graduate education (Landry, Jacobs, \& Newton, 2015). Graduate writing differs from EAL and undergraduate writing in that students are introduced to the academic writing associated with research proposals, research reports, and articles, yet the instruction and research of the academic writing genre in graduate courses is largely overlooked (Lavelle \& Bushrow, 2007). Through the neglect of writing instruction, graduate courses run the risk of writing being assessed only summatively, rather than both formatively and summatively. In some cases, graduate education is delivered through online instruction, necessitating deliberate planning for instructor and peer feedback in that particular context, as well as training for students in how to provide such feedback. While many research studies have indicated the benefits of embedded 
formative feedback in improving student's writing skills, the linchpin of this system is students' use of the feedback. If students are not willing to use the feedback in a meaningful way, then its potential to improve writing skills are minimized. As such, the ultimate value in embedding formative feedback is in its uptake and subsequent improvement of academic writing from the draft to final product.

In this study, we examined embedded instructor and peer feedback in an online graduate research course that required academic writing. Graduate students $(n=9)$ and their instructor at a North American university gave feedback on drafts of two pieces of academic writing. We investigated what type of feedback the instructor and peers gave and the degree to which students took up that feedback in their final versions. This study expands our understanding of formative assessment of academic writing by looking beyond which types of feedback are given to discover which are more likely to be used in final versions and to what extent.

\section{Literature}

Embedded formative feedback in writing can be a valuable part of writing instruction, as it allows for peers and instructors to provide comments and suggestions to writing drafts with the goal of improving the final product. Students have the opportunity to not only receive feedback on their own writing, but also have the chance to read their peers' work and provide constructive comments and suggestions. In this study, embedded formative feedback is defined as the provision of comments and corrections on surface- and meaning-level aspects that could improve the clarity and strength of the writing. Surface-level feedback, defined by Allen \& Mills (2016) as feedback focused on writing mechanics, was found by Eksi (2012) to be more commonly given by peers. However, meaning-level feedback, or comments focused on argumentation, flow, and content, embedded in the text by peers and instructors, led to the greatest improvement in 
writing (Patchan, Schunn, \& Correnti, 2016). Crucially, this feedback is not connected to grades (Liu \& Carless, 2006); it is connected solely to the improvement of the writing.

Research into embedded formative feedback is most plentiful in EAL contexts. In these contexts, instructors usually focus on providing linguistic-level corrections (Diab, 2015). When students perceive comments as harsh, these corrections are often met with mixed emotions by students, sometimes leading to a lack of acceptance of suggestions and pointing to the importance of neutral wording in the provision of feedback (Mahfoodh, 2017). Students' emotional evaluation of the feedback is vital to the likelihood of their use of the feedback. As such, it is important to consider the perceived tone of the feedback to maximize students' willingness of use the feedback. While the EAL context is less relevant to the context of this study since students are native speakers or must have a high proficiency of English to be in the program, this research sheds light on the importance of examining not only the giving of feedback, but also its uptake.

In similar research in undergraduate contexts, studies confirm that embedded formative feedback is considered beneficial for improving writing (Case, Williams, \& Xu, 2013; Stellmach, Keenan, Sandidge, Sippl, Konheim-Kalkstein, 2012). Instructor challenges include providing feedback to EAL and international students in undergraduate courses due to the perception that this feedback might not be well received (Case et al., 2013). Nelson and Schunn (2009) noted that the type of feedback from peers also influenced uptake, as students needed to understand the reason for the feedback. Again, this research in undergraduate contexts informs our research by highlighting factors that influence both the provision and uptake of feedback.

At the graduate level, less research into embedded formative feedback has been conducted (Landry, et al., 2015). However, from the available research, we learn that students 
value detailed, embedded feedback (Wolsey, 2008). While the provision of feedback is timeconsuming for both instructors and peers, students reported that the process can be intellectually challenging and effective in improving writing (Topping, Smith, Swanson, \& Elliot, 2000). However, critics also pointed out that students may only be using the feedback because they perceive the need to satisfy the instructor grading their paper (Stellmach, et al., 2012). Due to the lack of studies in this context, the research we do is crucial for investigating the effectiveness of embedded formative feedback from both peers and the instructor for the improvement of writing.

\subsection{Peer and Instructor Feedback}

Students view and respond to peer and instructor feedback differently (Ruegg, 2015). While most students are open to peer feedback, not all of them feel their peers are capable of giving helpful feedback (Wang, 2016).

Peers and instructors also give different types of feedback. Eksi (2012) noted that, compared to instructors, peers gave more surface-level feedback, focusing more on grammar and mechanics. Patchan, et al. (2016) also noted a type of peer feedback that involved praise and compliments, termed here rhetorical feedback. While increasing the likelihood of implementation (termed in this study as "uptake"), this rhetorical feedback did not lead to improved writing in the way that localized, meaning-level feedback did. In fact, Patchan, et al. (2016) found that the quality of the uptake, that is to say, the degree of implementation, was most influenced by whether or not the comment was localized (located directly where the problem occurs). This localization can take the form of marginal comments or comments embedded in the text, such as through the use of the Review functions in Microsoft Word. The literature characterizes peer feedback as helpful when specific and embedded in the text, but it points to a problem of uptake: while meaning-level feedback is most valuable for improving writing, it is 
not as readily taken up.

When examining instructor feedback, research reveals that students are more likely to respond to instructor feedback than peer feedback (Ruegg, 2015). This likelihood of uptake is influenced by the trust that students have in their instructors (Wang, 2016). However, Ferguson (2011) pointed out that formative feedback must be scheduled in such a way that students feel they have the time to take up the feedback. Thus, building trust and providing time for feedback uptake are important aspects of course design involving embedded formative feedback.

\subsection{The Role of Training in the Provision and Uptake of Feedback}

Considerable research has been done into the role of training in the provision and uptake of feedback. Nagori and Cooper (2014) called for the inclusion of formative feedback into course design at the graduate level but cautioned that training for students is needed for both the provision and uptake of feedback. Eksi (2012) noted that the provision of feedback improved over time, possibly due to the experience gained by students in providing feedback. Morra and Romano (2008) found that training influenced students' perception of the value of peer feedback, while Falchikov and Goldfinch (2000) emphasized the need for instructors and peers to follow clear criteria to overcome differences between peer and instructor feedback and thus mitigate differences in uptake. These studies highlight the benefits of providing students' training in providing and taking up feedback.

Yet, both the provision and uptake of feedback can be challenging. Providing and taking up feedback can be time-consuming (Topping et al. 2016), but that investment in time can result in reduced apprehension in giving feedback (Barnard, de Luca \& Li, 2015) and improved grades (Landry, et al., 2015). Part of the reduction of apprehension can come when students are trained to give feedback that is neutral, informative and thorough (Nilson, 2003), as well as substantive 
and embedded within the text (Patchan, et al., 2016). Through training, students can learn to improve these aspects of their provision of feedback.

As pointed out, surface level feedback is the most readily taken up, but meaning level feedback is more likely to result in improved writing (Patchan, et al., 2016). Ironically, the low proficiency writers who are most in need have been shown to incorporate significantly fewer suggestions than high proficiency writers (Allen \& Mills, 2016). These lower proficiency students are also the ones who benefit most from peer and instructor feedback when they do take up the suggestions (Landry, et al., 2015). Aspects that enhance the attitude necessary for students to be willing to take up feedback include: a non-threatening atmosphere (Morra \& Romano, 2008); timing (Baker, 2016) and skilled reviewers (Patchan, et al., 2016). Thus, training in taking up feedback is connected to course design and training in giving feedback.

\subsection{Learning Errors and Formative Feedback (LEAFF) Model}

One conceptual tool for understanding the uptake of embedded formative feedback is the Learning Errors and Formative Feedback (LEAFF) model (Leighton, Chu, \& Seitz, 2013; Leighton, Tang, \& Guo, 2017). The LEAFF model emphasizes that when students consider a learning environment to be emotionally safe, it allows them to feel at ease revealing their misconceptions and take risks during the formative phases of learning. When students feel safe in acknowledging and sharing their misunderstandings, instructors can help correct these misconceptions by providing relevant formative feedback that is specifically targeted to the misunderstandings revealed. In turn, students are expected to be more receptive to this feedback than they would be otherwise because the feedback is more meaningful (Leighton, et al. 2017). The LEAFF model, shown in Figure 1, involves three parts. This study focused on the second part of the model, highlighted with a dashed line in Figure 1, which focuses on students' 
emotional evaluation and use of the provided feedback.

\section{[INSERT FIGURE 1]}

Since this paper focused on the second part of the LEAFF model, only this part is discussed in this literature review. For a description of the full model, please refer to Leighton and colleagues' 2013 chapter. The second part of the LEAFF model focuses on students' mental models of the learning environment. Student who view their learning environment as emotionally safe are likely to possess mental models that allow them to demonstrate misunderstandings on formative assessments and interpret formative feedback as more relevant and useful in guiding their learning. This relevant feedback is deemed formative which is hypothesized to be used by students in a meaningful way, while irrelevant feedback is labeled feckless and often dismissed by students (Leighton et al., 2013).

After creating a positive instructional climate, it is important to consider other factors that may contribute to students' evaluation and use of the formative feedback. As such, this study focuses on Part 2 of the model by investigating the type of feedback that is deemed formative and most likely to be used by students.

Using the LEAFF Model to guide this study, we established three research questions to investigate embedded formative feedback in a graduate course:

1. To what extent did participants integrate feedback on their writing assignments?

2. How did the uptake of instructor and peer feedback differ?

3. How did the uptake of surface- and meaning-level feedback differ?

\section{Method}

To investigate students' uptake of peer and instructor feedback, data was collected from two assignments administered in an online graduate-level writing course. All of the students 
were part of the same cohort and familiar with each other. A key feature of the course was collaboration, which entailed extensive small group work, in which students developed the trust necessary to create a positive environment so that they may give each other meaningful feedback in the form of detailed feedback on two written assignments (Tasks $1 \& 2$ ) prior to submission. These two assignments were connected to each other and could either be based on an action research project or an independent inquiry. The two options for the first assignment (Task1) were an ethics application or a research proposal, and the second assignment (Task 2) was a report on the research itself.

\subsection{Participants}

Students in this study were in their $11^{\text {th }}$ and penultimate class in an online Master of Education program with a specialization in Teaching English as an Additional Language. The students were all either native speakers of English, or had native-like proficiency, as they were all teachers of English taking part in a graduate degree program in an English-medium university. Since the language proficiency for all participants was required to be high to be accepted in a graduate program, we did not control for first language.

Within the first week of class, the learners were invited via an email by a research assistant to participate in the study. Of the 16 students in the class, nine consented to participate. Of the nine participants, two completed ethics applications for Task 1, while seven of them chose the research proposal. All nine students had to complete the research report for Task 2. This study was approved by the Institutional Ethics Review Board of the participating university, and ethical protocols were followed throughout this study. For example, because the instructor was the Principal Investigator of the study, all communication between participants was mediated by the research assistant to ensure that the instructor was not aware of which students were 
participants until after the course grade appeal deadline had passed.

The instructor of this course had a background in education with over 5 years of experience teaching at the graduate level. The research assistants, too, had educational and research backgrounds in adult education and teaching English as an Additional language, having both graduated from the institution's Master of Education in Teaching English as Additional Language some years prior. The first research assistant had a $\mathrm{PhD}$ in the field, and the second was a doctoral candidate in the same field.

\subsection{Peer and Instructor Feedback Process and Training}

During the initial synchronous online-class session, the instructor explained the value of taking risks while learning and described the importance of peer and instructor feedback. Although this study did not investigate the instructional climate, part 1 of the LEAFF model, previous studies have indicated that students who receive a scripted explicit discussion designed to develop a positive and trusting learning environment at the start of a class or learning task identify more areas of weaknesses during the learning process (Leighton \& Bustos Gomez, 2018) and show stronger academic performances on complex tasks (Chu, 2017). As such, this study utilized a similar scripted explicit discussion at the start of the course to elicit a trusting learning environment. With the LEAFF Model part 2 in mind, the purpose of this explanation was to set up peer and instructor feedback as a norm in this course, thereby encouraging students to develop mental models accepting of feedback.

In the online learning management system, groups of three or four students had their own discussion board and online room to host virtual meetings. On the draft deadline date for Tasks 1 and 2, students posted their drafts to the discussion board and had six days to respond to each of their colleagues' work. Students followed an agreed-upon rotation established by the group such 
that no one student was the first to provide feedback to more than one other student's work. The first student responded using the Review functions in Microsoft Word because research has shown that electronic feedback is successful in eliciting revisions (Ene \& Upton, 2014). That student then uploaded the new version for the next student to review. Once all of the group members had reviewed the paper, the instructor provided feedback to the latest version, adding her comments to those previously given. After all the feedback was offered, students then had six days to review the comments, make changes, and submit the final version by the assignment deadline. The giving, receiving, and subsequent uptake of peer feedback links the design of this course with the third part of the LEAFF Model, which emphasizes student performance.

Students received the following training in giving feedback: first, expectations for feedback were made clear in a rubric which governed their grade for active construction of knowledge in the course (Task 3). This Task 3 rubric was included in the course outline and reviewed during the first online class session. Second, when the instructor noticed that some students were overusing the comment feature in Microsoft Word, resulting in long strings of comments that moved off of the original page, she requested that they make surface-level changes directly in the text where the writer could choose to "accept" or "reject" the change. This request was made in the hopes that students would engage more readily with a change right in front of them than a comment they would have to scroll to the end of the document to read and address. Thirdly, after the first round of peer feedback, the instructor used a rubric to provide ungraded comments to each individual peer reviewer. These comments were given as part of the training on how to improve feedback. Training focused on providing students with clear criteria for the provision of feedback. 


\subsection{Procedures for Coding Feedback}

After the students' draft and final assignments were collected, each feedback item and case of student feedback uptake was coded independently by two research assistants who subsequently compared their codes and came to consensus. Codes were given to each piece of feedback. In cases where multiple feedback items were included in one comment, separate codes were assigned accordingly. The Effective Writing Test Detailed Marking Code (EWT-C) guided this process (Effective Writing Programme, 1993). The EWT-C consists of 172 different error codes in eight different sections: content, grammar, structure, word use, paragraphing, spelling, punctuation, and sentences.

For the purposes of this study, slight modifications were made to the EWT-C to aid in coding. The error codes within seven of the original eight EWT-C main sections, grammar, structure, word use, paragraphing, spelling, punctuation, and sentences, were collapsed into one code for the entire category; a newly-added APA category was also introduced. The only section that was not completely collapsed in this way was the content category: the original EWT-C content category had 14 subcategories, and it was reduced it to four content subcategories for this study. This was done because a substantial amount of feedback focused on content and the entire category itself was deemed too broad to be totally collapsed. Procedures for coding, along with the code descriptions, are described in Appendix A.

The nine categories were then further divided into surface-level, meaning-level, and rhetorical feedback. Surface-level feedback included the grammar, sentence, word, spelling, punctuation, and APA codes, which are considered easier to address because the writer need only click "accept change." The content, paragraph, and structure codes were deemed to be meaninglevel feedback, which is not as straightforward to address, and requires more reworking to be 
integrated. During the coding process, the raters noticed a high quantity of rhetorical feedback, which did not offer students suggestions to enhance their assignments. This type of feedback included positive feedback, which offered encouragement, and discussion feedback, which discussed the content of the paper. A couple instances of unclear feedback and erroneous feedback, the latter which provided information contrary to the expectations of the assignment, or something incorrect in terms of grammar or APA style, were also noted.

After each piece of feedback was coded into the categories and levels, the raters also coded students' use of the feedback. The use of surface-level and meaning-level feedback was split into two categories: quantity of feedback items addressed and quality of uptake. Each occurrence of feedback was coded and tallied as either peer or instructor feedback. This process provided the frequency counts of the quantity of feedback items. The quality of uptake was determined by whether feedback was accepted either wholly or partially, or if it was rejected/not addressed. After each piece of feedback was coded to provide a quality rating, a percentage score for each code category was calculated based on how much of the rate of uptake addressed and the suggested change. This procedure provided a score for quality of uptake. Since rhetorical and erroneous feedback did not warrant responses from students, no uptake score was calculated for these feedback items. Table 1 outlines the final codes, along with examples of feedback from the data set.

[INSERT TABLE 1]

\subsection{Analysis}

Feedback items were analyzed and tallied. Due to the small sample size, descriptive statistics were selected over analytical statistics, as even non-parametric statistics did not result in 
statistically significant differences ${ }^{1}$.

\section{Findings}

The uptake for each feedback item was determined following the procedure outlined in the previous section. Quantity of feedback integrated for each of the situations outlined in the research questions is presented first and documented in Tables 1 to 4 . The quality of feedback, expressed as percentages, is presented second and documented in Table 3. Both quality and quality inform our three research questions.

\subsection{Quantity of uptake}

To measure the quantity of feedback addressed (research question [RQ1]), we compared the number of instances of feedback identified with the number taken up by the student. The frequency counts for each type of feedback is shown in Appendix B. Excluding rhetorical feedback $(n=626)$, there were 1873 instances of coded feedback in which uptake was suggested. Of that, the quantity of feedback addressed in final submissions was 1590. In other words, students integrated feedback items on their writing assignments approximately $84.89 \%$ of the time, as shown in Table 2.

\section{[INSERT TABLE 2]}

Comparing uptake of peer and instructor feedback (RQ2) illustrates the extent to which the students integrated feedback from both sources. Students addressed $89.26 \%$ of the instructor feedback, whereas only $82.95 \%$ of the feedback provided by their peers were addressed, as shown in Table 3.

[INSERT TABLE 3]

\footnotetext{
${ }^{1}$ We did run non-parametric statistics, and no significant differences were identified. We suspect this is due to the small sample size $(n=9)$. Additionally, we used an alpha value of 0.01 because several comparisons were conducted, so a Bonferroni comparison was needed to ensure the Type 1 Error rate was not inflated.
} 
Comparing uptake of surface- and meaning-level feedback (RQ3), the data reveal $89.44 \%$ of the surface-level feedback was addressed while only $79.08 \%$ of the meaning-level feedback was addressed by students, as shown in Table 4 . The rate of uptake was variable, with $73.16 \%$ for peer meaning-level feedback addressed, which had the lowest uptake rate, and $93.55 \%$ of instructor surface-level feedback, which had the highest uptake rate. These percentages illustrate a preference for addressing instructor feedback over peer feedback as well as surface-level feedback over meaning-level feedback.

[INSERT TABLE 4]

\subsection{Quality of uptake}

Quality of uptake was determined by assigning a percentage value to the uptake, since students might accept a suggestion wholly, to some degree (expressed as a percentage), or not at all. The percentages of quality of uptake for each category is shown in Appendix C. While the total quantity of uptake (RQ1) was $84.89 \%$ the quality of uptake was $77.51 \%$.

When considering quality of instructor versus peer feedback uptake (RQ2), students tended toward higher quality of uptake when addressing instructor feedback rather than peer feedback (see Table 5). Although there were no statistically significant differences between the uptake of peer and instructor surface- and meaning-level feedback, students addressed instructor feedback $(85.87 \%)$ to a greater degree when compared to peer feedback $(73.50 \%)$.

\section{[INSERT TABLE 5]}

Comparing quality of uptake of surface-level vs. meaning-level feedback (RQ3), the data reveal that students had a marginally higher quality of uptake for surface-level feedback (see Table 6). The total quantity of surface-level feedback that was either partially or wholly accepted was $89.44 \%$ while the quality of uptake for the feedback was $78.16 \%$. The quantity of meaning- 
level feedback that were either partially or wholly accepted was $79.08 \%$ while the quality of uptake for the feedback was $76.56 \%$.

[INSERT TABLE 6]

\section{Discussion}

The findings from this study reveal the extent to which students took up feedback in an online graduate research course. We discuss the findings by returning to each of the research questions:

1. To what extent did participants integrate feedback on their writing assignments?

Overall, students took up feedback at a high rate of quantity $(>80 \%)$ and quality $(>75 \%)$. These findings are similar to Stellmach, et al., (2012) who found that student writing improved through a review-revise-resubmit activity built into the research course. The electronic feedback in the form of Track Changes and Comment features in Word lent itself well to the online course format. As in Baker (2016), students substantially revised their work based on feedback. These findings reinforce our understanding that embedded formative feedback improves student writing and is therefore a worthwhile component of graduate courses and, as evidenced by this study, can take place through online delivery.

2. How did the uptake of instructor and peer feedback differ?

In comparing instructor and peer feedback, there were no significant differences in the quantity and quality of uptake. Students did tend to prefer their instructor's feedback and took it up more often and to a greater extent. Perhaps their instructor's feedback carried greater significance for them (Wolsey, 2008): they may have viewed their instructor as an expert, or they may simply have integrated this feedback knowing their instructor would be assessing and grading their final submission, as noted by Stellmach et al. (2012). However, the lack of significant difference in uptake between peer and instructor feedback suggests that they were open to peer feedback and saw it as valuable (Wang, 2016). These findings underscore the place and suitability of both 
instructor and peer formative feedback in graduate courses.

3. How did the uptake of surface and meaning-level feedback differ?

In comparing surface with meaning-level feedback uptake, there was no significant difference. Unlike the students in Baker (2016), students in this study tended to take up surface-level feedback more frequently, but this is likely due to the ease of uptake; they could simply right click and choose "accept change" in Word rather than rework an entire section, as might have been necessary with meaning-level feedback. Meaning-level feedback required substantial changes to the text: returning to the literature, rewording a section, or reorganizing the paper (Baker, 2016). We recognize the work the students did invest in taking up meaning-level feedback, but we are also driven to inquire as to what would be needed to increase that uptake. With these findings, we enhance our understanding that the provision of embedded formative feedback does not guarantee uptake.

In reviewing the above findings for all three research questions, we return to the nature and extent of training as a potential explanation for the results. In this course, it is evident that some research-informed practices were helpful. The feedback was electronic (Ene \& Upton, 2014), localized in the text (Patchan, et al., 2016) and timely (Baker, 2016). However, it is also clear that the instructor made the initial assumption that the students were capable and possibly experienced at giving feedback, without checking at the outset whether that was the case. Since Allan \& Mills (2016) noted that writer proficiency influenced uptake of suggestions, the range of proficiency among the students may also have been a factor in the integration of feedback in this course. The instructor provided some training in the form of clarifying expectations by providing a rubric, discussing criteria, and responding to needs as they arose. However, this training was possibly insufficient. The literature reveals that there are other aspects of training that were 
overlooked, such as providing an exemplar or practice exercise (Nagori \& Cooper, 2014). With regards to the LEAFF model, these findings suggest that the implementation of instructor and peer feedback in this course enhanced students' mental models of learning and influenced their learning and assessment performance (Part 2), but that the nature and extent of the training may not have been sufficient to ensure that all feedback used in a meaningful way. As a result, some of the feedback that was given was rhetorical and some of the feedback given was not taken up (Leighton, Chu \& Seitz, 2013).

To further our understanding of formative feedback in graduate courses, we have compiled an appendix of research-informed training strategies for instructors to facilitate the provision and uptake of formative feedback (see Appendix D).

\section{Conclusion}

In light of the findings regarding the quantity and quality of feedback uptake in this study, we conclude that embedded formative feedback in graduate courses can be an important aspect of course design for the improvement of writing skills. We observed uptake, the desired outcome of the inclusion of draft deadlines, and feedback loops. However, there was a difference in quantity and quality that suggests that students either partially rejected some aspects of the instances of feedback because they did not find them valuable or they were not able to accept them. This inability to accept feedback may be due to a lack of knowledge or skill on the part of the feedback givers or the students who received it. This study highlights the need for research to understand student reasoning behind their decision-making in taking up feedback, either wholly, partially, or not at all.

As there were no significant differences in the amount and uptake of peer and instructor feedback, we may conclude that students find them equally valuable. However, we are also left 
to wonder if this is a limitation of our study design. Peers had the first look at drafts and therefore the first opportunity to notice instances for improvement. Do these figures actually indicate that peer feedback is equally valuable since it took three peers to come up with a similar quantity of feedback to the instructor, who looked at the draft last? Additional research might look at student perception in this regard or investigate a study design with two control groups: one with feedback from the instructor first and one with it last, so as to see if the order of viewing impacts the results.

We also found that surface-level feedback was taken up in greater quantity and quality than meaning-level feedback. In addition, compared to the instructor, peers were more likely to give this type of feedback. Both aspects point to either a limitation in the study design or support a call for enhancing the training students receive in providing feedback. Regarding study design, since the peers viewed the documents first and the instructor did not necessarily repeat comments made by peers, the surface-level changes that needed to be made could be pointed out by peers long before the instructor viewed the document. This might explain a lack of surface-level feedback from the instructor, however, this does not rule out peers giving meaning-level feedback. It suggests instead that students might have been less equipped to give meaning-level feedback due to a lack of training. We maintain the need for research into student training on the provision and reception of feedback.

Given the focus of this particular graduate program on teaching English as a Second Language, we recognize the likelihood of students being advanced EALs, rather than native speakers of English. We acknowledge that by not controlling for first language spoken, it is possible that any EALs in the group might have behaved differently from the rest of the participants (e.g., focused more accepting or giving surface-level feedback). We would have 
required a larger sample size to be able to do so and suggest that an aspect of future research would be to collect data about first language spoken as well as English proficiency and to compare the uptake behavior of EALs vs native speakers of English in this context.

In the course studied, having peers work as a group to provide feedback was ideal for dealing with the time challenge associated with embedded formative feedback (Wolsey, 2008). Reviewers could build on previous feedback without having to repeat it, and the instructor could focus on meaning-level feedback without being bogged down by mechanics. As well, since the instructor's feedback appeared to carry more weight, that meaning-level feedback may have been considered more because it originated with the instructor, permitting a deeper revision of work and a better final submission.

We conclude then that to improve the quantity and quality of feedback uptake, instructors are advised to include explicit training in both giving and receiving formative feedback from peers and instructors, rather than assume from their status as graduate students that students know how to manage embedded formative feedback. While the sample size of our study was small and this limited the generalizability of our findings, we conclude that embedded formative feedback led to improved written products for both assignments in this course, and we suggest that future research examine the role of explicit training in the provision and reception of feedback, which is important for improving our understanding of the use of embedded formative feedback in course design. 


\section{References}

Allen, D., \& Mills, A. (2016). The impact of second language proficiency in dyadic peer feedback. Language Teaching Research, 20(4), 498-513.

Baker, K.M. (2016). Peer review as a strategy for improving students' writing process. Active Learning in Higher Education, 17(3), 170-192.

Barnard, R., de Luca, R., \& Li, J. (2015). First-year undergraduate students' perceptions of lecturer and peer feedback: A New Zealand action research project. Studies in Higher Education, 40 (5), 933 - 944.

Case, R.E., Williams, G.M., \& Xu, W. (2013). Instructors' feedback among generation 1.5 students, international students and basic writers. Journal on Excellence in College Teaching, 24(1), 85-103.

Diab, N.M. (2015). Effectiveness of written corrective feedback: Does type of error and type of correction matter? Assessing Writing, 24, $16-34$.

Effective Writing Programme. (1993). Detailed marking code. Retrieved from http://people.ucalgary.ca/ rseiler/code.htm

Eksi, G.Y. (2012) Peer review versus teacher feedback in process writing: How effective? International Journal of Applied Educational Studies, 13(1), 34 - 48.

Ene, E., \& Upton, T. (2014). Learner uptake of teacher electronic feedback in ESL composition. System, 46, 80-95.

Falchikov, N. \& Goldfinch, J. (2000). Student peer-assessment in higher education: A metaanalysis comparing peer and teacher marks. Review of Educational Research, 70(3), 287322.

Ferguson, P. (2011). Student perceptions of quality feedback in teacher education. Assessment \& 
Evaluation in Higher Education, 36(1), 51-62.

Landry, A., Jacobs, S., \& Newton, G. (2015). Effective use of peer assessment in a graduate level writing assignment: A case study. International Journal of Higher Education, 4(1), $38-51$.

Lavelle, E. \& Bushrow, K. (2007). Writing Approaches of Graduate Students. Educational Psychology, 27 (6), 807-822.

Leighton, J. P., \& Bustos Gomez, M. C. (2018). A pedagogical alliance for trust, wellbeing and the identification of errors for learning and formative assessment. Educational Psychology: An International Journal of Experimental Educational Psychology, 38(3), 381-406. doi: 10.1080/01443410.2017.1390073

Leighton, J. P., Chu, M.-W., \& Seitz, P. (2013). Cognitive diagnostic assessment and the learning errors and formative feedback (LEAFF) model. In R. Lissitz (Ed.), Informing the practice of teaching using formative and interim assessment: A systems approach (pp. 183207). Charlotte, NC: Information Age Publishing.

Leighton, J.P., Tang, W., \& Guo, Q. (2017). Undergraduate students' attitudes towards mistakes in learning and academic achievement. Assessment and Evaluation in Higher Education. doi: $10.1080 / 02602938.2017 .1387230$

Liu, N-F., \& Carless, D. (2006). Peer feedback: The learning element of peer assessment. Teaching in Higher Education, 11(3), 279-290.

Lu, J. \& Law, N. (2012). Online peer assessment: Effects of cognitive and affective feedback. Instructional Science, 40, 257- 275. https://doi.org/10.1007/s11251-011$9177-2$

Mahfoodh, O.H.A. (2017). “I feel disappointed”: EFL university students' emotional responses 
towards teacher written feedback. Assessing Writing, 31, $53-72$.

Morra, A.M., \& Romano, M.E. (2008). University students' reactions to guided peer feedback of EAP compositions. Journal of College Literacy and Learning, 35, 19- 30.

Nagori, R. \& Cooper, M. (2014). Key principles of peer assessments: A feedback strategy to engage the postgraduate international learner. The IAFOR Journal of Education, 2(2), 211238.

Nelson, M.M., \& Schunn, C.D. (2009). The nature of feedback: How different types of peer feedback affect writing performance. Instructional Science, 37, 375 - 401.

Nilson, L.B. (2003). Improving student peer feedback. College Teaching, 51(1), 34 - 38.

Oxford Brookes University. (2011). ASKe. Retrieved from http://www.brookes.ac.uk/aske/

Patchan, M.M., \& Schunn, C.D. (2015) Understanding the benefits of providing peer feedback: How students respond to peers' texts of varying quality. Instructional Science, 43, 591614.

Patchan, M.M., Schunn, C.D., \& Correnti, R.J. (2016). The nature of feedback: How peer feedback features affect students' implementation rates and quality of revisions. Journal of Educational Psychology, 108, 1098 - 1120.

Ruegg, R. (2015). Differences in uptake of peer and teacher feedback. RELC Journal, 46 (2), 131-145.

Sambell, K. (2011). Rethinking feedback in higher education: An assessment for learning perspective. ESCalate. Bristol, UK. Retrieved from www.escalate.ac.uk

Stellmach, M.A., Keenan, N.K., Sandidge, R.R., Sippl, A.L., \& Konheim-Kalkstein, A.L. (2012). Review, revise, and resubmit: The effects of self-critique, peer review, and instructor feedback on student writing. Teaching of Psychology, 39(4), 235-244. 
Topping, K.J., Smith, E.F., Swanson, I., \& Elliot, A. (2000). Formative peer assessment of academic writing between postgraduate students. Assessment \& Evaluation in Higher Education, 25 (2), 149 - 149.

Wallace, D. L., \& Hayes, J. R. (1991). Redefining revision for freshmen. Research in the Teaching of English, 54-66.

Wang, W. (2016). Peer feedback in Chinese college English writing class: Using action research to promote students' English writing. Journal of Language Teaching and Research, 7(5), $958-966$.

Wolsey, T.D. (2008). Efficacy of instructor feedback on written work in an online program. International Journal on E-Learning, 7(2), 311 - 329. 


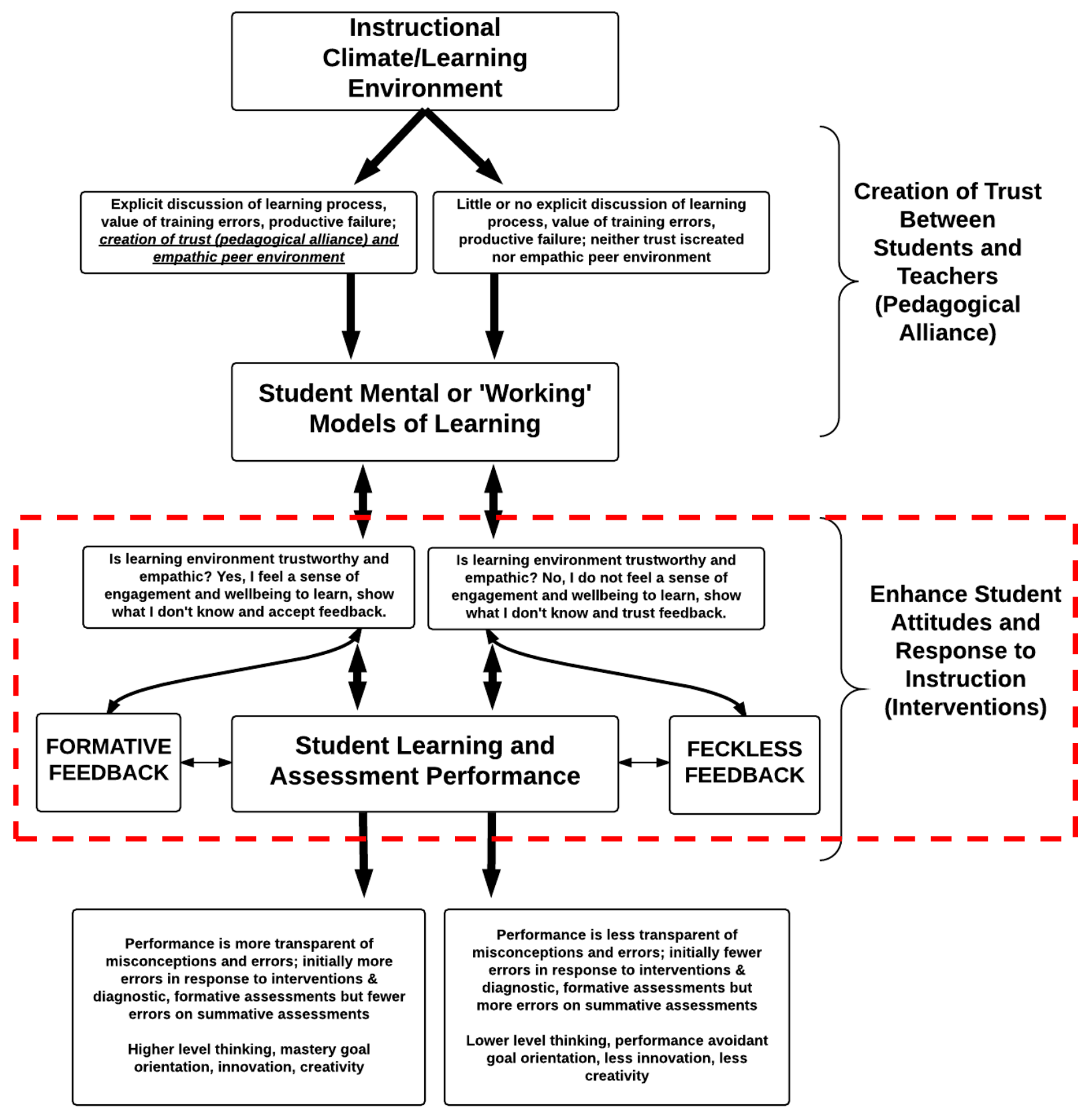

Figure 1. Learning Errors and Formative Feedback Model.

Adapted from. Leighton, Tang and Guo, (2017). Reprinted with permission. 
Table 1

Examples of the Feedback Identified in Each Sub-Category

\begin{tabular}{|c|c|}
\hline Type of Feedback & Examples of Feedback from Writing Assignment Tasks \\
\hline \multicolumn{2}{|l|}{ Surface-Level Feedback } \\
\hline Grammar & "This increased confident" - Confidence? \\
\hline Word Use & $\begin{array}{l}\text { What about using a different verb to avoid repetition? } \\
\text { What about "observed" or "reported"? }\end{array}$ \\
\hline Spelling & "inititially" - initially \\
\hline Punctuation & added comma \\
\hline APA Formatting & Second level of heading (See APA Manual, $p$ 62) \\
\hline \multicolumn{2}{|l|}{ Meaning-Level Feedback } \\
\hline Not enough information or detail & $\begin{array}{l}\text { Stemming from? } \\
\text { What is the purpose of this quote, can you link it to what } \\
\text { follows? }\end{array}$ \\
\hline $\begin{array}{l}\text { Unnecessary or irrelevant } \\
\text { information/detail }\end{array}$ & $\begin{array}{l}\text { In my opinion this section looks too long. Do you think you may } \\
\text { skip some repetitive parts or blend them into other sections? }\end{array}$ \\
\hline $\begin{array}{l}\text { Confusing or incorrect } \\
\text { information/detail }\end{array}$ & $\begin{array}{l}\text { Hyland and Hyland (2006) predate Ellis (2009) so they can not } \\
\text { EXPAND to Ellis, which this sentence implies. }\end{array}$ \\
\hline $\begin{array}{l}\text { Further resources/literature } \\
\text { suggested }\end{array}$ & $\begin{array}{l}\text { I recommend including a citation from Smith as support for this } \\
\text { idea. }{ }^{*}\end{array}$ \\
\hline Structure/Organization & $\begin{array}{l}\text { Do you think it would be better to include this paragraph in the } \\
\text { methodology section? }\end{array}$ \\
\hline Paragraphing & $\begin{array}{l}\text { This would be a good intro to this section (suggestion to change } \\
\text { order of sentences in paragraph) }\end{array}$ \\
\hline & $\begin{array}{l}\text { Do you think it might be better to remove this sentence and } \\
\text { combine this and the following paragraph into one? }\end{array}$ \\
\hline Sentence Errors & $\begin{array}{l}\text { "The important will add..." - Something is odd about this } \\
\text { sentence. }\end{array}$ \\
\hline \multicolumn{2}{|l|}{ Rhetorical Feedback } \\
\hline Discussion & $\begin{array}{l}\text { This made me think of Jane's* paper } \\
\text { This is also true from my experience }\end{array}$ \\
\hline Positive Feedback, general & $\begin{array}{l}\text { Great! } \\
\text { Good Point! }\end{array}$ \\
\hline $\begin{array}{l}\text { Positive Feedback, substantive } \\
\text { Erroneous Feedback } \\
\text { Correction of Error Feedback }\end{array}$ & $\begin{array}{l}\text { Excellent section - clearly defines the purpose of the study } \\
\text { It appears you have all the required components listed here. } \\
\text { You need to follow the organization from the course outline. } \\
\text { See my explanation in the comment by your title. }\end{array}$ \\
\hline Information & $\begin{array}{l}\text { Please see the Adobe connect slides for how to do this } \\
\text { automatically with Word }\end{array}$ \\
\hline
\end{tabular}

Note. All feedback comments are italicized, while examples of student writing are shown within quotes.

*The example is a generic example based on feedback a few instances from the data set. 
Table 2

Quantity and Percentage of Total Feedback Items Identified and Addressed in the Two Writing Assignment Tasks Combined

\begin{tabular}{lccc} 
& & \multicolumn{2}{c}{ Total } \\
\cline { 2 - 4 } & $\begin{array}{c}\text { Number of feedback items } \\
\text { identified }\end{array}$ & $\begin{array}{c}\text { Number of feedback items } \\
\text { addressed }\end{array}$ & $\begin{array}{c}\text { Percentage of feedback items } \\
\text { addressed }\end{array}$ \\
\hline $\begin{array}{l}\text { Surface-level feedback } \\
\text { Meaning-level }\end{array}$ & 1051 & 940 & $89.44 \%$ \\
feedback & 822 & 650 & $79.08 \%$ \\
Total & 1873 & 1590 & $84.89 \%$ \\
\hline
\end{tabular}

Table 3

Quantity and Percentage of Peer and Instructor Feedback Items Identified and Addressed in the Two Writing Assignment Tasks Combined

\begin{tabular}{lcccccc}
\hline & $\begin{array}{c}\text { Number of } \\
\text { feedback items } \\
\text { identified }\end{array}$ & $\begin{array}{c}\text { Number of } \\
\text { feedback items } \\
\text { addressed }\end{array}$ & $\begin{array}{c}\text { Percentage of } \\
\text { feedback items } \\
\text { addressed }\end{array}$ & $\begin{array}{c}\text { Number of } \\
\text { feedback items } \\
\text { identified }\end{array}$ & $\begin{array}{c}\text { Number of } \\
\text { feedback items } \\
\text { addressed }\end{array}$ & $\begin{array}{c}\text { Percentage of } \\
\text { feedback items } \\
\text { addressed }\end{array}$ \\
\hline $\begin{array}{l}\text { Surface-level } \\
\text { feedback }\end{array}$ & 834 & 737 & $88.37 \%$ & 217 & 203 & $93.55 \%$ \\
$\begin{array}{l}\text { Meaning- } \\
\text { level } \\
\text { feedback }\end{array}$ & 462 & 338 & $73.16 \%$ & 360 & 312 & $86.67 \%$ \\
Total & 1296 & 1075 & $82.95 \%$ & 577 & 515 & $89.26 \%$ \\
\hline
\end{tabular}

Table 4

Percentage of Peer and Instructor Feedback Items Identified and Addressed in the Two Writing Assignment Tasks Combined

\begin{tabular}{lccc}
\hline & Peer & Instructor & Total \\
\hline Surface-level feedback & $88.37 \%$ & $93.55 \%$ & $89.44 \%$ \\
Meaning-level feedback & $73.16 \%$ & $86.67 \%$ & $79.08 \%$ \\
Total & $82.95 \%$ & $89.26 \%$ & $84.89 \%$ \\
\hline
\end{tabular}


Table 5

Percent Averages of the Quality of Uptake in the Two Writing Assignment Tasks Combined

\begin{tabular}{lccc}
\hline & Peer & Instructor & Total \\
\hline Surface-Level Feedback & $75.30 \%$ & $88.55 \%$ & $78.16 \%$ \\
Meaning-Level Feedback & $69.58 \%$ & $84.13 \%$ & $76.56 \%$ \\
Total & $73.50 \%$ & $85.87 \%$ & $77.51 \%$
\end{tabular}

Note. Each of these percent averages were calculated using the weighted means formula

Table 6

Percentage of Quantity and quality of Peer and Instructor Feedback Items Identified and Addressed in the Two Writing Assignment Tasks

\begin{tabular}{|c|c|c|}
\hline & Quantity & Quality \\
\hline Surface-level feedback & $89.44 \%$ & $78.16 \%$ \\
\hline Meaning-level feedback & $79.08 \%$ & $76.56 \%$ \\
\hline Total & $84.89 \%$ & $77.51 \%$ \\
\hline
\end{tabular}


Appendix B

Quantity of Feedback Items Identified and Addressed in the Two Writing Assignment Tasks Combined

\begin{tabular}{|c|c|c|c|c|}
\hline & \multicolumn{2}{|c|}{ Peer } & \multicolumn{2}{|c|}{ Instructor } \\
\hline & $\begin{array}{c}\text { Number of feedback } \\
\text { items identified }\end{array}$ & $\begin{array}{l}\text { Number of feedback } \\
\text { items addressed }\end{array}$ & $\begin{array}{c}\text { Number of feedback } \\
\text { items identified }\end{array}$ & $\begin{array}{c}\text { Number of feedback } \\
\text { items addressed }\end{array}$ \\
\hline \multicolumn{5}{|l|}{ Surface-level feedback } \\
\hline Grammar & 214 & 196 & 36 & 33 \\
\hline Word Use & 168 & 156 & 83 & 78 \\
\hline Spelling & 29 & 28 & 8 & 6 \\
\hline Punctuation & 104 & 78 & 3 & 4 \\
\hline APA Formatting & 319 & 279 & 87 & 82 \\
\hline Total surface-level feedback & 834 & 737 & 217 & 203 \\
\hline \multicolumn{5}{|l|}{ Meaning-level feedback } \\
\hline Not enough information or detail & 138 & 79 & 60 & 48 \\
\hline $\begin{array}{l}\text { Unnecessary or irrelevant } \\
\text { information/detail }\end{array}$ & 39 & 32 & 31 & 26 \\
\hline $\begin{array}{l}\text { Confusing or incorrect } \\
\text { information/detail }\end{array}$ & 46 & 34 & 50 & 44 \\
\hline $\begin{array}{l}\text { Further resources/literature } \\
\text { suggested }\end{array}$ & 4 & 11 & 2 & 2 \\
\hline Structure/Organization & 85 & 51 & 101 & 85 \\
\hline Paragraphing & 47 & 39 & 60 & 55 \\
\hline Sentence Errors & 103 & 92 & 56 & 52 \\
\hline Total meaning-level feedback & 462 & 338 & 360 & 312 \\
\hline \multicolumn{5}{|l|}{ Rhetorical Feedback } \\
\hline Positive Feedback, substantive & 158 & 0 & 15 & 0 \\
\hline Positive Feedback, general & 208 & 0 & 13 & 0 \\
\hline Positive Feedback, repetitive & 24 & 0 & 12 & 0 \\
\hline Discuss & 119 & 0 & 6 & 0 \\
\hline Unclear & 9 & 0 & 0 & 0 \\
\hline Extra Information & 7 & 0 & 18 & 0 \\
\hline Erroneous Feedback & 19 & 0 & 0 & 0 \\
\hline Correction of Error Feedback & 6 & 0 & 12 & 0 \\
\hline Total rhetorical feedback & 550 & 0 & 76 & 0 \\
\hline Total & 1846 & 1075 & 653 & 515 \\
\hline
\end{tabular}


Appendix C

Percent Averages of the Quality of Uptake in the Two Writing Assignment Tasks for each Category

\begin{tabular}{|c|c|c|c|}
\hline & Peer & Instructor & $\begin{array}{l}\text { Peer and } \\
\text { Instructor } \\
\text { Combined }\end{array}$ \\
\hline Surface-Level Feedback & 75.30 & 88.55 & 78.16 \\
\hline Grammar & 71.60 & 84.69 & 73.49 \\
\hline Word Use & 77.76 & 84.98 & 80.16 \\
\hline Spelling & 91.35 & 75.00 & 88.46 \\
\hline Punctuation & 69.37 & 100.00 & 70.86 \\
\hline APA Formatting & 76.58 & 93.95 & 80.52 \\
\hline Meaning-Level Feedback & 69.58 & 84.13 & 76.56 \\
\hline Not enough information or detail & 66.54 & 73.87 & 69.31 \\
\hline Unnecessary or irrelevant information/detail & 84.37 & 81.31 & 83.00 \\
\hline Confusing or incorrect information/detail & 70.17 & 81.24 & 76.41 \\
\hline Further resources/literature suggested & 96.97 & 100.00 & 97.44 \\
\hline Structure/Organization & 63.62 & 84.89 & 76.92 \\
\hline Paragraphing & 72.22 & 90.37 & 82.84 \\
\hline \multirow[t]{2}{*}{ Sentence Errors } & 65.73 & 89.00 & 74.13 \\
\hline & 73.50 & 85.87 & 77.51 \\
\hline
\end{tabular}

Note. Each of these percent averages were calculated using the weighted means formula 